\title{
EFFECT OF ANIONS IN SEAWATER TO CORROSION ATTACK ON PASSIVE ALLOYS
}

\author{
A. Ismail $^{1}$, N.E. Loren ${ }^{2}$, N.F. Abdul Latiff ${ }^{3}$ \\ Faculty of Mechanical and Manufacturing Engineering, Universiti Tun Hussein Onn Malaysia, Johor, Malaysia, \\ azzura@uthm.edu.my ${ }^{I}$ \\ cd100019@siswa.uthm.edu.my \\ noorfareezalatiff@gmail.com ${ }^{3}$
}

\begin{abstract}
Some metals and alloys have special characteristics that enable them to provide superior corrosion-resistant metal surfaces. These protective passive films are responsible for the phenomenon of passivity. Metals with this characteristic can be categorized as passive materials such as stainless steel $316 \mathrm{~L}$ and nickel alloy Inconel 625. However, in corrosive environment this protective passive film may breach and exposed bare metal for further corrosion attack. Corrosive environment can be refer as metal is susceptible to corrosion attack such as seawater which contain aggressive ions (salt) with negative charge (anion). An electrochemical test has been carried out to determine the effect of anion on corrosion attack of $316 \mathrm{~L}$ and Inconel 625. The objective is to identify the breakdown potential $\left(E_{b}\right)$ in different anion ratio (chloride $(\mathrm{Cl})$ : sulphate $\left(\mathrm{SO}_{4}{ }^{2-}\right)$. The anions concentration was decided as $\mathrm{Cl}^{\mathrm{V}}: \mathrm{SO}_{4}{ }^{2-} ; 35: 0,25: 10,10: 25,0: 35$ and was compared to artificial seawater, 3.5\% NaCl. The pH values were set in neutral in static condition. The materials were run for cyclic polarization with a scan rate of $2 \mathrm{mV} / \mathrm{sec}$. The $E_{b}$ value for $316 \mathrm{~L}$ decreased in every solution as the temperature increased from $30^{\circ} \mathrm{C}$ to $80^{\circ} \mathrm{C}$. The results explain that $\mathrm{SO}_{4}^{2-}$ has inhibiting effect to passive alloy showing that the highest $E_{b}$ value detect at $30^{\circ} \mathrm{C}$ and highest concentration of $\mathrm{SO}_{4}^{2-}$. Optical observations elucidate that, the number of pits increased in high concentration of $\mathrm{Cl}^{-}$than $\mathrm{SO}_{4}^{2-}$. Both materials presents pits reducing as the temperature and concentration of $\mathrm{SO}_{4}^{2-}$ ions increased. Nevertheless, the $E_{b}$ value for $316 \mathrm{~L}$ is likely to has a competition effect between $\mathrm{Cl}^{-}$and $\mathrm{SO}_{4}{ }_{4}^{2-}$ anion as the graph shows no significant effect at $\mathrm{Cl}^{-}: \mathrm{SO}_{4}{ }^{2-}, 25: 10,10: 25$. The same scenario is not shown by Inconel 625 because this metal is highly corrosion resistance compared to $316 \mathrm{~L}$.
\end{abstract}

Index Terms: 316L, Inconel 625, Anions, Sulphate, Chloride, Breakdown potential

\section{INTRODUCTION}

Corrosion is a natural phenomenon that can divide into several types based on its mechanism. Two general class of corrosion are uniform and localized. Uniform attack normally characterized by a chemical or electrochemical reaction that proceeds uniformly over the entire exposed surface or over the large area while localized corrosion is defined as the selective removal of metal by corrosion at small area on a metal surface in contact with a corrosive environment such as liquid. The major corrosion parameters are listed as dissolved salts, oxidizing agents, temperature and $\mathrm{pH}$. Salts are minerals that dissolve in water. They include potasium $\left(\mathrm{K}^{+}\right)$, chloride $\left(\mathrm{Cl}^{-}\right)$, sodium $\left(\mathrm{Na}^{+}\right)$, sulphate $\left(\mathrm{SO}_{4}{ }^{2-}\right)$, magnesium $\left(\mathrm{Mg}^{2+}\right)$, and calcium $\left(\mathrm{Ca}^{2+}\right)$. These are present in higher concentrations in seawater than in freshwater [1].

\subsection{Seawater}

Seawater is a highly corrosive electrolyte to all kind of metals. The aim of this study is to identify the behavior of aggressive anions on passive alloy. Anions are one of the parameter that affects corrosion attack on metals including corrosion resistance alloys (CRAs) such as 316L and Inconel 625. It is exist everywhere especially in seawater. Although the composition of anions in seawater is only minimal, it can bring a massive impact to material's degradation. As corrosion can be explained as deterioration of material with environment, anion can be considered as one of the main factor that affects corrosion attack namely sulphate $\left(\mathrm{SO}_{4}{ }^{2-}\right)$ and chloride $\left(\mathrm{Cl}^{-}\right)$.

\subsection{Passive material}

Steel is an alloy of iron and other elements including carbon. Steel become stainless when it contain a minimum of $10.5 \%$ chromium. Stainless steel $316 \mathrm{~L}$ is the low carbon version of 316 and is immune from sensitisation. It contains $16-18 \%$ composition of chromium [2,3]. The composition chromium is a chemical reaction which is improved corrosion resistance in stainless steel. The better corrosion resistance is due to a chromium oxide film that is formed on the steel surface. Effects of corrosion on the metal structure can be seen from two important aspects in terms of aesthetic and ability. In terms of aesthetic, corrosion attacks the surface of 
material where it causes the surface to be damaged and dirty while the effects in terms of the ability was evident from the ability of such metal in a long time.

\subsection{Basis of Corrosion Reactions}

Aqueous corrosion is an electrochemical process that occurs at the interface between a material (commonly, but not exclusively, a metal) and an aqueous solution. For corrosion to occur, an oxidation reaction (metal dissolution and/or metal oxide formation) and a reduction reaction (proton, water, or dissolved oxygen reduction) must occur simultaneously. Materials may also be subject to deterioration in high-temperature environments.

\subsection{Passivity}

All metals and alloys, with the exception of gold, have a thin protective film - a corrosion product-present on their surface resulting from reaction with the environment. These films prevent the metals from reverting back to the thermodynamically stable condition of their origin, the ores used to produce them. Some of these films - the passive films - on some, but not all, metals and alloys have special characteristics that enable them to provide superior corrosion-resistant metal surfaces. These protective passive films are responsible for the phenomenon of passivity.

\subsection{Corrosion mechanism}

Corrosion phenomena can be measured by electrochemistry process. It is a process involved a reaction between metal and electrical energy and occurs when the electrical current impose into the water. The chemical reactions that occur are reduction-oxidation reaction. These reactions require a species of material that oxidized such as metal and another thing that is reduced is such as the oxidizing agent. Thus, it can divide into two simultaneous reactions. The oxidation of a metal is happen at an anode while the reductions of a substance happen in cathode. In oxidation process, the metal losses electrons and in a reduction process, the oxidizing agents gain the electrons that have been shed by the metal.

\section{METHODOLOGY}

The sample was soldered and embedded in resin for polishing with identified surface area. It was grind with 2401200grit SiC paper and wet polish with 600-grit SiC paper until previous coarse scratch by sectioning are removed. The hardness and microstructure was observed before and after corrosion attack using Potentiaostat/galvanostat in conjunction with three electrodes. The solutions (electrolyte) also were prepared with different sulphate and chloride ratio and electrochemistry was run for cyclic potentiodynamic polarization (CPP) measurement at different temperatures $\left(30^{\circ} \mathrm{C}, 50^{\circ} \mathrm{C}\right.$ and $\left.80^{\circ} \mathrm{C}\right)$.

For CPP measurement, after the current density reaches a preset value of $500 \mu \mathrm{A} / \mathrm{cm}^{2}$, the potential then gradually returns to the open circuit potential. The breakdown potential, $E_{b}$ ( the least noble potential where corrosion will initiate and propagate) is then identified, which is the potential where the current increases with increasing potential. The polarization scan is plotted as potential versus logarithm of the current.

\section{RESULTS AND DISCUSSION}

Generally, the results show that chloride $\left(\mathrm{Cl}^{-}\right)$ions is an aggressively anion than sulphate $\left(\mathrm{SO}_{4}{ }^{2-}\right)$ ions which propagate to the corrosion attack. For Vickers hardness test, it can be clearly observed that the changes in the material hardness after the corrosion attack increased as the temperature and the concentration of chloride $\left(\mathrm{Cl}^{-}\right)$ions increases. Figure 1 and 2 shows the different hardness value on Stainless Steel 316L and Inconel 625 before and after corrosion attack in five solutions in three different temperatures which is $30^{\circ} \mathrm{C}, 50^{\circ} \mathrm{C}$ and $80^{\circ} \mathrm{C}$ respectively. Hardness covers several properties of metal such as resistance to deformation, resistance to friction and abrasion. The reduction in hardness is usually accompanied by an increase in ductility, thereby decreasing the brittleness of the metal. In overall, the greater the hardness of the metal, the greater resistance it has to deformation. The hardness values of Stainless Steel are significant to corrosion attack but the hardness values are not significant on Inconel 625. This is because Inconel 625 is very tough and high in corrosion resistance (uniform corrosion).

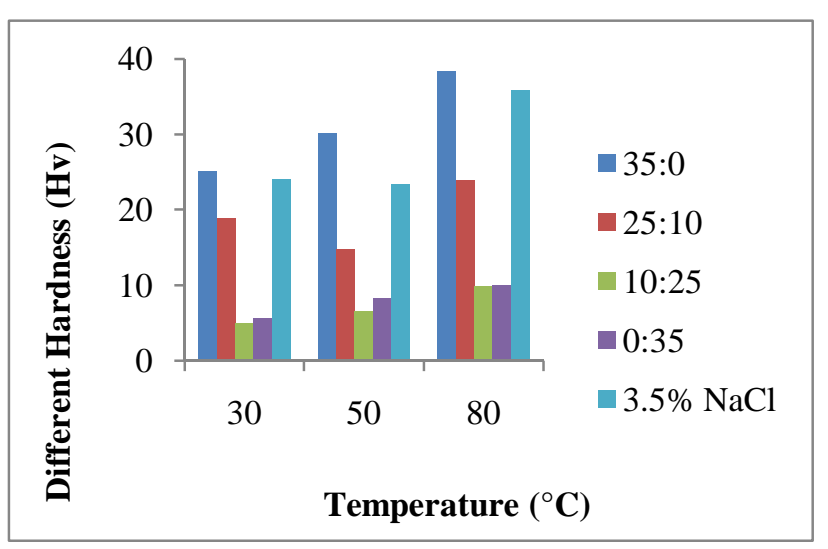

Figure 1:Different hardness of stainless steel 316L after corrosion attack with different ratio of $\mathrm{Cl}^{-}: \mathrm{SO}_{4}{ }^{2-}$

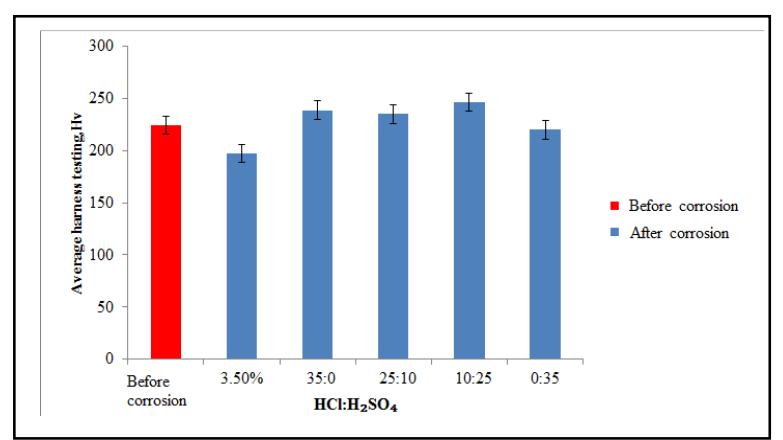

Figure 2: Hardness value of Inconel 625 before and after corrosion attack in $3.5 \% \mathrm{NaCl}$, and different $\mathbf{C l}^{-}: \mathbf{S O}_{4}{ }^{2-}$ ratio; $35: 0,25: 10,10: 25,0: 35$ 
From the Figure 3 to 7 shows the CPP plot for stainless steel $316 \mathrm{~L}$ in $\mathrm{Cl}^{-}: \mathrm{SO}_{4}{ }^{2-}$ value $35: 0,25: 10,10: 25,0: 35$ and in $3.5 \%$ $\mathrm{NaCl}$ respectively at $30^{\circ} \mathrm{C}, 50^{\circ} \mathrm{C}$ and $80^{\circ} \mathrm{C}$. All the polarizations presents as positive hystheresis (forward scan are higher than reverse scan) which explained that the materials has possibility to be attacked by pitting corrosion as passive film breaks. The lowest breakdown potential $\left(E_{b}\right)$ values were found at highest solution of chloride $\left(\mathrm{Cl}^{-}\right)$ concentration at $80^{\circ} \mathrm{C}$ followed by the corresponding values of chloride $\left(\mathrm{Cl}^{-}\right)$and sulphate $\left(\mathrm{SO}_{4}{ }^{2-}\right)$ at the lowest temperature. From the result of the cyclic polarization studies, it is contingent that breakdown potential $\left(E_{b}\right)$, is shifted to more negative value with the increasing of chloride $\left(\mathrm{Cl}^{-}\right)$concentration and temperature. This shows that the pitting potential is more active at the high concentration of ion chloride $\left(\mathrm{Cl}^{-}\right)$.

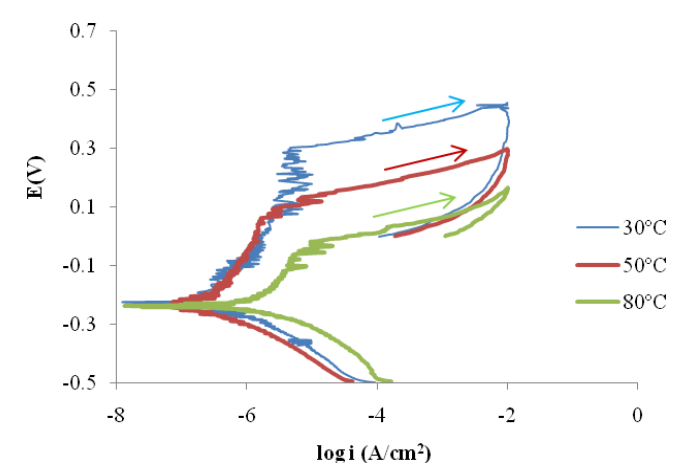

Figure 3: CPP for stainless steel 316 $\mathrm{L}$ in $\mathrm{Cl}^{-}: \mathrm{SO}_{4}{ }^{2-}$ 35:0

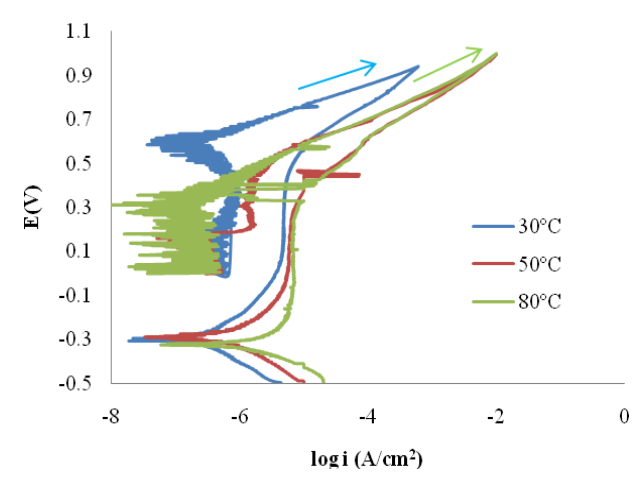

Figure 4: CPP for stainless steel $316 \mathrm{~L}_{\text {in }} \mathrm{Cl}^{-}: \mathrm{SO}_{4}{ }^{2-} 25: 10$

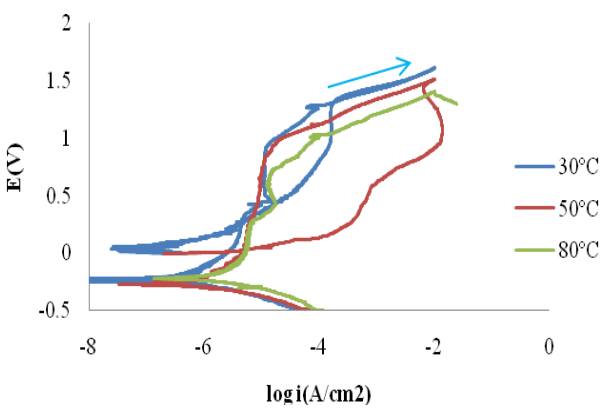

Figure 5: CPP for stainless steel $316 \mathrm{~L}_{\text {in }} \mathrm{Cl}^{-}: \mathrm{SO}_{4}{ }^{2-} 10: 25$

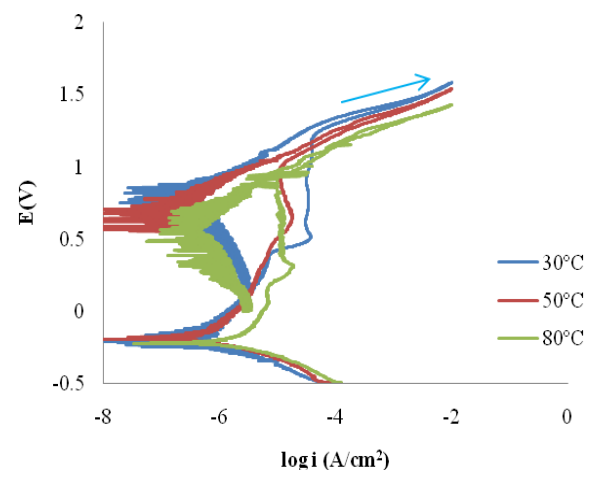

Figure 6: CPP for stainless steel $316 \mathrm{~L}^{\text {in }} \mathrm{Cl}^{-}: \mathrm{SO}_{4}{ }^{2-} 0: 35$

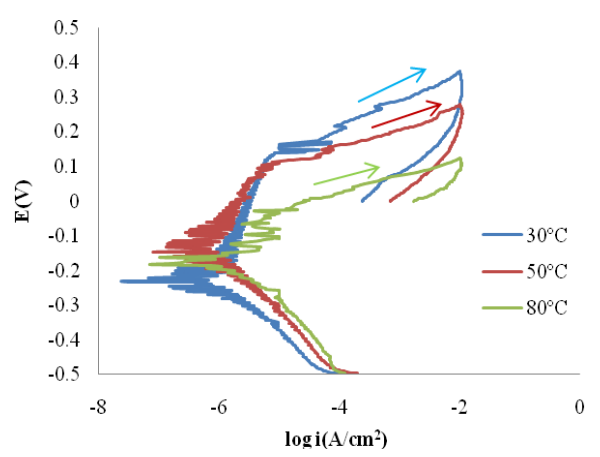

Figure 7: CPP for stainless steel 316L in $3.5 \% \mathrm{NaCl}$

Temperature is a critical factor in pitting corrosion. Figure 8 is a plot of breakdown potential $\left(E_{b}\right)$ of solution in three different temperatures. The results show a shift of breakdown potential $\left(E_{b}\right)$ to more effective value as the temperature increases. At low temperatures, extremely high breakdown potential $\left(E_{b}\right)$ are observed. At higher temperatures, the pitting potential decrease. The microstructure evaluation shows that heavy pit density occurs at the higher temperatures but in smallest pit depth.

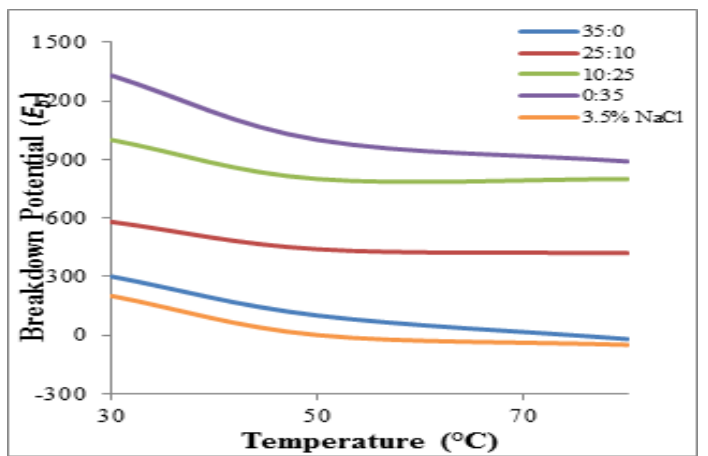

Figure 8: Breakdown potential of stainless steel $316 \mathrm{~L}$ in $3.5 \% \mathrm{NaCl}$ and different $\mathrm{Cl}^{-}: \mathrm{SO}_{4}{ }^{2-}$ ratio at increasing temperature.

In other words, the process of pit nucleation at high temperature is more unstable. These indicate that stainless steel $316 \mathrm{~L}$ exhibit a higher pitting resistance at low temperature in seawater. Moreover, with rise in the 
temperature, the physical structure of the passive film is affected resulting in variation of pitting corrosion.

The CPP also was run for Inconel 625 in different $\mathrm{Cl}^{-}: \mathrm{SO}_{4}{ }^{2-}$ ratio at $30^{\circ} \mathrm{C}$ as shown in Figure 9. All the polarisaion behaves as negative hystheresis (forward scan is lower than reverse scan) which explains that pitting might not occur on Inconel 625 after passive film breaks.

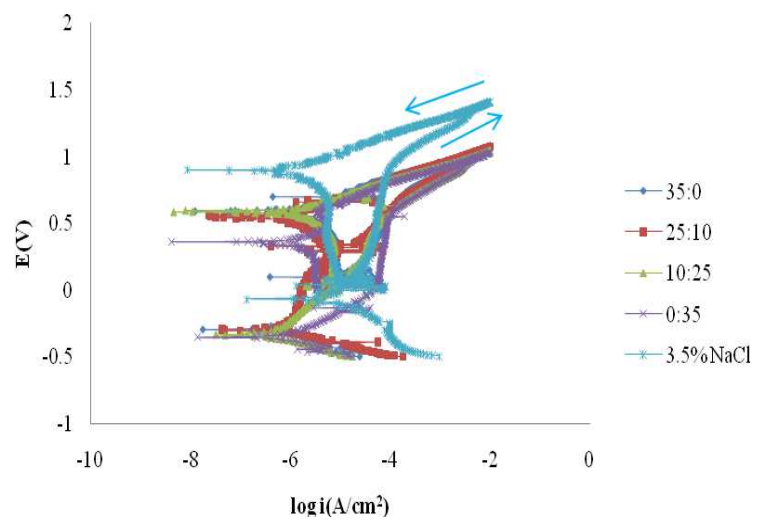

Figure 9: $\mathrm{CPP}$ of Inconel 625 in different $\mathrm{Cl}^{-}: \mathrm{SO}_{4}{ }^{2-}$ ratio at $30^{\circ} \mathrm{C}$.

Inconel 625 is a stainless steel in nickel alloy group. The The main reason for nitrogen alloying in Inconel 625 is to increase the mechanical strength of the steel and to replace some of the expensive nickel alloying element. In addition, increased nitrogen content can also increase the resistance to localised corrosion and retard the precipitation of the carbide and intermetallic phases [4]. Figure 10 presents the breakdown potential $\left(E_{b}\right)$ of Inconel 625 in different solution ratio. The highest $E_{b}$ value in obtained by Inconel 625 in $3.5 \% \mathrm{NaCl}$ and varying the chloride-sulphate ratio does not give any significant effect to Inconel 625 as this material is very resistance to corrosion attack. This is contradict as what presented by stainless steel 316L which shown that stainless steel is highly corrosion in $3.5 \% \mathrm{NaCl}$ (lowest $E_{b}$ value in Figure 8).

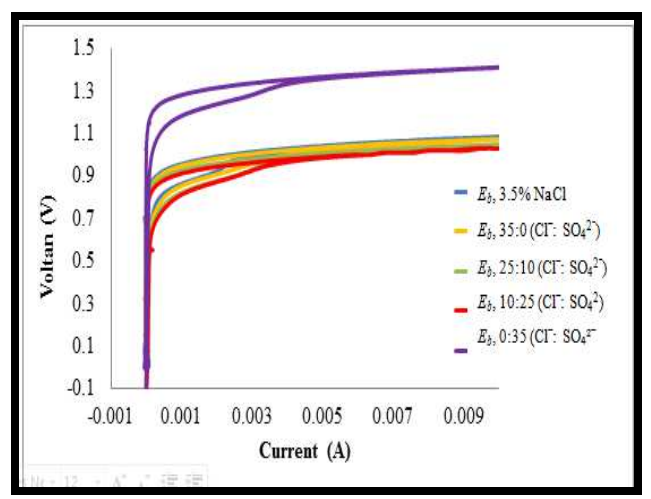

Figure 10: Potential versus current for Inconel 625 in different chloride-sulphae ratio.

The difference in microstructure that occurs before and after test shows that the corrosion effect is become worst at the highest temperature for each solution. For stainless steel
$316 \mathrm{~L}$, the maximum of pits was found on a specimens immersed in solution with high concentration of chloride $\left(\mathrm{Cl}^{-}\right)$as shown in Figure 10. This is closely related to the different hardness test value after the corrosion test. As the hardness value of the sample reduce, the resistance of a material to plastic deformation also decreased. This is due to the hardness of the sample decreased after the corrosion attack. In the presence of chloride $\left(\mathrm{Cl}^{-}\right)$or other halide ions, the resistance of stainless steels to pitting corrosion is enhanced by higher chromium (Cr), molybdenum (Mo), and nitrogen $(\mathrm{N})$. However, the pit also severe observed when stainless steel $316 \mathrm{~L}$ in $3.5 \% \mathrm{NaCl}$ as shown in Figure 11. The value of chromium ( $\mathrm{Cr}$ ), molybdenum (Mo), and nitrogen $(\mathrm{N})$ for stainless steel $316 \mathrm{~L}$ are $16.5,2$ and 10 respectively. When crevice corrosion is initiated, for high alloyed stainless steel with PREn $>40$ immersed in seawater, it is possible for it to propagate at much lower temperature than when initiated. The PREn value for stainless steel 316L is 23.1 and it have high tendency to pitting and therefore it not used for seawater applications.

For Inconel 625, the optical observation presents no pitting attack except some minor of corrosion products developed on the surface. This significant to the CPP plot which shown that Inconel behaves as negative hystheresis in all solutions.
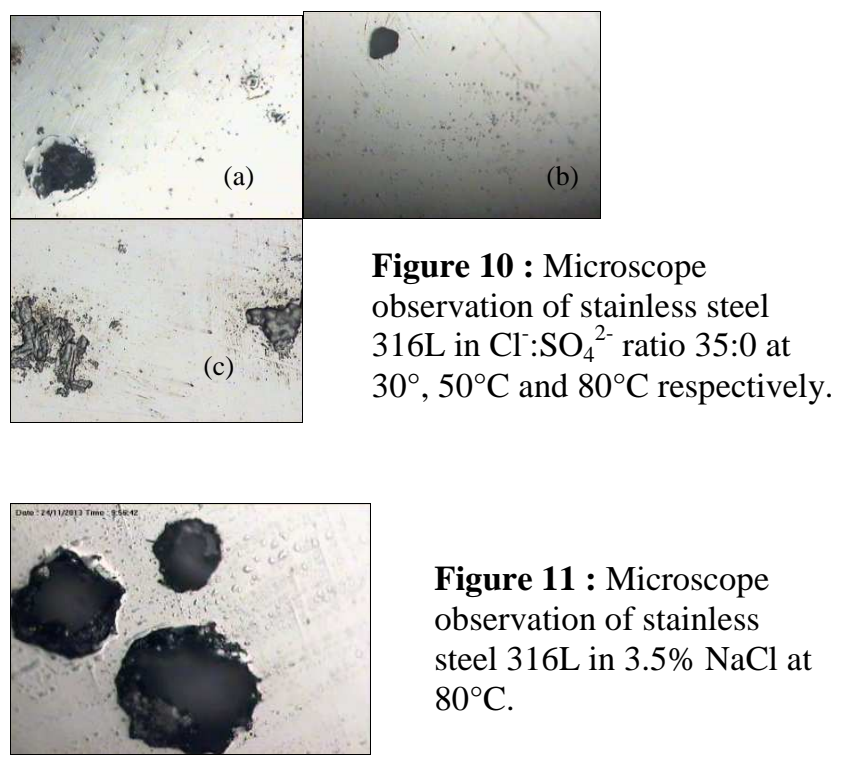

Figure 11: Microscope observation of stainless steel $316 \mathrm{~L}$ in $3.5 \% \mathrm{NaCl}$ at $80^{\circ} \mathrm{C}$.

\subsection{CONCLUSIONS}

The susceptibility to pitting corrosion of austenitic stainless steel $316 \mathrm{~L}$ and Inconel 625 increased as the chloride $\left(\mathrm{Cl}^{-}\right)$ ion concentration increased in seawater. However, the pits hole does not observed on Incoenal 625 . The breakdown potential $\left(E_{b}\right)$ of stainless steel $316 \mathrm{~L}$ in seawater solutions is greatly influenced by the temperature and the concentration of ions chloride $\left(\mathrm{Cl}^{-}\right)$in seawater. It can be proved by the data obtained from the electrochemistry test. Increasing the temperature from $30^{\circ} \mathrm{C}$ to $80^{\circ} \mathrm{C}$ would decrease the breakdown potential $\left(E_{b}\right)$ value in each solution. The OCP, breakdown potential $\left(E_{b}\right)$ and passive range of stainless steel $316 \mathrm{~L}$ is decrease as the temperature and chloride ion concentration increased. Other than that, the different of hardness value and the number of pits on the sample surface 
also increased as the temperature increased which indicate a greater degradation of the corrosion resistance of stainless steel 316L. At high chloride $\left(\mathrm{Cl}^{-}\right)$content, chloride $\left(\mathrm{Cl}^{-}\right)$ions were the species responsible for pitting since the pit morphology was the same as that observed in solutions containing chloride $\left(\mathrm{Cl}^{-}\right)$only. In this study, sulphate $\left(\mathrm{SO}_{4}{ }^{2-}\right)$ ions also had accelerating effect but are not responsible for pitting corrosion. The PREn value for stainless steel $316 \mathrm{~L}$ is 23.1 and it is therefore it not used for seawater applications.

\section{ACKNOWLEDGEMENT}

The authors would like to acknowledge the Universiti Tun Hussein Onn Malaysia and Ministry of Higher Education Malaysia (MOHE) for funded this research.

\section{REFERENCES}

[1]. Cicek, V. \& Al-Numan, B., (2011), "Corrosion Chemistry”, Canada: Scrivener Publishing LLC, pg 18, 19, 28.

[2]. Chawla, S.L. \& Gupta, R.K., (1993), "Material Selection for Corrosion Control", ASM International, Page 122.

[3]. Premkumar, S.L., (2008), "Prep Manual for Undergraduates: Orthodontics”, Elsevier, pg 277.

[9].Manganon P.L., The Principles of Materials Selection for Eingineering Design, Prentice Hall, 1999, pp.512-535.

\section{BIOGRAPHIES}

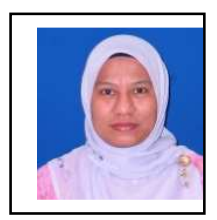

A.Ismail is a lecturer in Universiti Tun Hussein Onn Malaysia and has more than 10 years experience in teaching and research. Corrosion and related material degradation is the main interest of her.

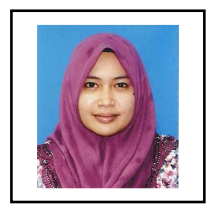

N.E. Loren is a final year student at Universiti Tun Hussein Onn Malaysia under the supervision of A. Ismail.

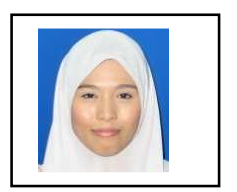

N.F. Abdul Latiff is a final year student at Universiti Tun Hussein Onn Malaysia under the supervision of A. Ismail. 